\title{
Development of a Reverse Genetic System for Studying Rose Rosette Virus in Whole Plants
}

\author{
Jeanmarie Verchot,,$^{1,2,+}$ Venura Herath, ${ }^{1,2,3}$ Cesar D. Urrutia, ${ }^{2}$ Mathieu Gayral, ${ }^{1}$ Kelsey Lyle, ${ }^{4}$ \\ Madalyn K. Shires, ${ }^{2}$ Kevin Ong, ${ }^{2}$ and David Byrne ${ }^{5}$ \\ ${ }^{1}$ Texas A\&M Agrilife Center in Dallas, 17360 Coit Rd, Dallas, TX, U.S.A. \\ ${ }^{2}$ Department of Plant Pathology \& Microbiology, Texas A\&M University, College Station, TX, U.S.A. \\ ${ }^{3}$ Department of Agricultural Biology, Faculty of Agriculture, University of Peradeniya, 20400, Sri Lanka \\ ${ }^{4}$ Department of Biological Sciences, The University of Texas at Dallas, Dallas, TX, U.S.A. \\ ${ }^{5}$ Department of Horticulture Sciences, Texas A\&M University, College Station, TX, U.S.A. \\ Accepted 13 July 2020.
}

\begin{abstract}
Rose rosette virus (RRV) is a negative-sense RNA virus with a seven-segmented genome that is enclosed by a double membrane. We constructed an unconventional minireplicon system encoding the antigenomic (ag)RNA1 (encoding the viral RNAdependent RNA polymerase [RdRp]), agRNA3 (encoding the nucleocapsid protein $[\mathrm{N}]$ ), and a modified agRNA5 containing the coding sequence for the iLOV protein in place of the P5 open reading frame (R5-iLOV). iLOV expression from the R5iLOV template was amplified by activities of the RdRp and $N$ proteins in Nicotiana benthamiana leaves. A mutation was introduced into the RdRp catalytic domain and iLOV expression was eliminated, indicating RNA1-encoded polymerase activity drives iLOV expression from the R5-iLOV template. Fluorescence from the replicon was highest at 3 days postinoculation (dpi) and declined at 7 and $13 \mathrm{dpi}$. Addition of the tomato bushy stunt virus (TBSV) P19 silencing-suppressor protein prolonged expression until 7 dpi. A full-length infectious clone system was constructed of seven binary plasmids encoding each of the seven genome segments. Agro-delivery of constructs encoding RRV RNAs 1 through 4 or RNAs 1 through 7 to $N$. benthamiana plants produced systemic infection. Finally, agro-delivery of the full-length RRV infectious clone including all segments produced systemic infection within $60 \mathrm{dpi}$. This advance opens new opportunities for studying RRV infection biology.
\end{abstract}

Keywords: Emaravirus, infectious clone, plant virus, reverse genetic system, translation and replication

Constructed DNA copies (cDNAs) of viral genomes that can be transcribed to produce infectious virus are used for reverse genetic analysis to uncover the functions of coding and

${ }^{\dagger}$ Corresponding author: J. Verchot; jm.verchot@tamu.edu

Funding: This work was funded by the United States Department of Agriculture's National Institute of Food and Agriculture (NIFA) Specialty Crop Research Initiative project "Combating Rose Rosette Disease: Short Term and Long-Term Approaches" (2014-51181-22644/SCRI) and The American Rose Society (gift).

*The $\boldsymbol{e}$-Xtra logo stands for "electronic extra" and indicates there is a supplementary table published online.

The author(s) declare no conflict of interest.

๑) 2020 The American Phytopathological Society noncoding sequences (Ahlquist et al. 1984). The key to the successful construction of infectious cDNA is to produce viral RNA progeny with intact $5^{\prime}$ and $3^{\prime}$ ends and no extra bases that could inhibit replication. To achieve a correct $5^{\prime}$ end, the genomic cDNA is fused to the bacteriophage T7, SP6, or cauliflower mosaic virus (CaMV) $35 \mathrm{~S}$ promoters (Bedoya and Daròs 2010; Chikh Ali et al. 2011; Desbiez et al. 2012; Flatken et al. 2008). Transcription terminators, and in some cases, the selfcleaving hepatitis delta virus ribozyme (HDVrz) are used to create precise 3' ends (Bordat et al. 2015; Boyer and Haenni 1994; Lindbo 2007). Reporter genes such as green fluorescent protein (GFP) and its derivatives $\beta$-glucuronidase, luciferase, or $i L O V$ coding sequences have also been incorporated into infectious clones (Chapman et al. 2008; Dolja et al. 1992; Lindbo 2007; Sempere et al. 2011; Shivprasad et al. 1999). Combining visual markers of infection with reverse genetic technology has been used for microscopic observation and spectrophotometric quantification of the effects of targeted mutations on virus infection. These technologies have also been central to exploring molecular plant-virus interactions occurring in susceptible hosts or interactions that govern genefor-gene resistance (Boyer and Haenni 1994; Dolja et al. 1992; Feng et al. 2019; Stobart and Moore 2014).

Minireplicons contain only the essential machinery for virus replication and gene expression. For positive- and negativestrand RNA viruses, a minireplicon typically consists of viral replication factors provided in trans to replicate a viral RNA produced from a cDNA template (Ganesan et al. 2013; Hoenen et al. 2013; Qian et al. 2017; Sasvari et al. 2014). For bunyaviruses, which have negative-strand RNA genomes, the RNAdependent RNA polymerase (RdRp) and the nucleocapsid $(\mathrm{N})$ protein are the two essential viral proteins for transcription and producing replication-competent ribonucleoprotein (RNP) particles (Sun et al. 2018). By cotransfecting plasmids encoding the viral glycoproteins, the RNPs can be packaged into virus-like particles (VLP) (Neumann et al. 2002).

The first minireplicon and infectious clone of a negativestrand RNA virus that infects plants was sonchus yellow net virus (SYNV) (family Rhabdoviridae) (Ganesan et al. 2013; Jackson et al. 2018; Wang et al. 2015). The SYNV full-length cDNA was introduced into a binary vector fused to a duplicated CaMV $35 S$ promoter. For the minireplicon, the RdRp, N, and phosphoprotein (P) must be provided in trans (Jackson et al. 2018). The first reverse genetic system or minireplicon system for a segmented negative-strand RNA virus infecting plants was for tomato spotted wilt virus (TSWV) (family Tospoviridae) 

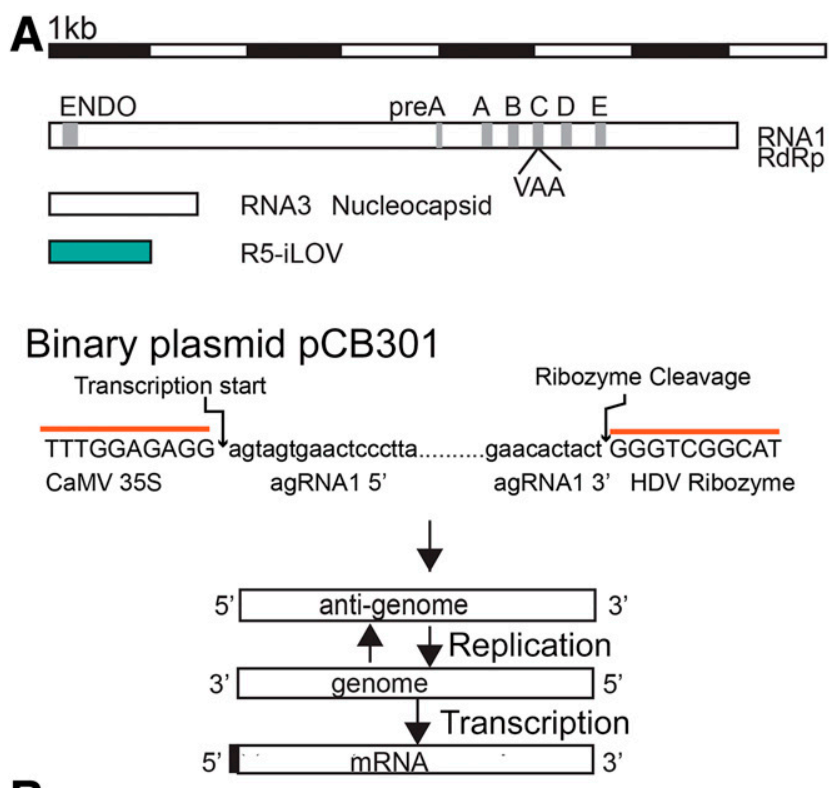

B

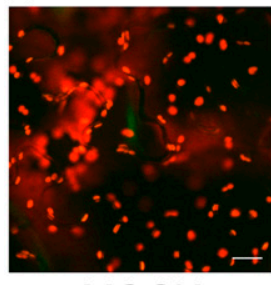

MOCK

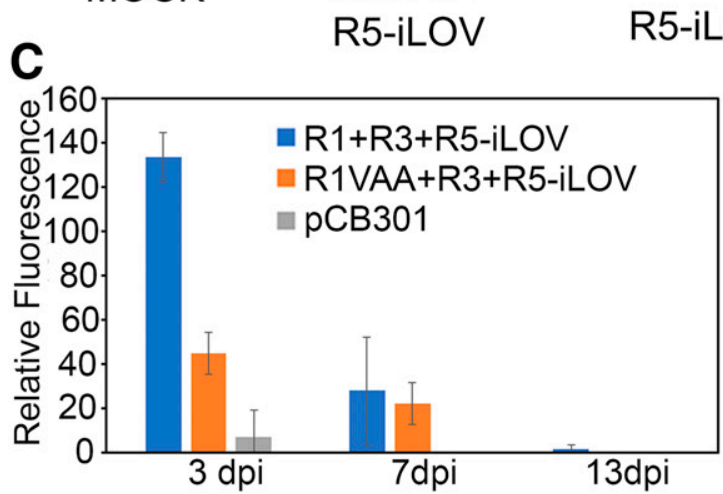

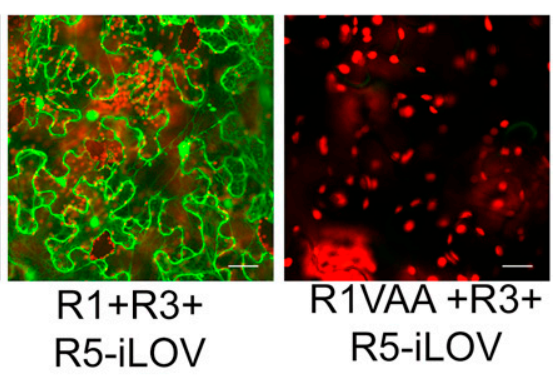

Fig. 1. System of binary constructs encoding RNA1, RNA3, and R5-iLOV agroinfiltrated into Nicotiana benthamiana leaf epidermal cells. A, The cDNA segments for the RNA1, RNA3, and R5-iLOV construct are depicted. The size of each segment is indicated by the upper 1-kb ruler. The conserved endonuclease (ENDO) and polymerase motifs (preA, A, B, C, D, and E) are identified in the RNA-dependent RNA polymerase open reading frame by gray boxes. The nucleocapsid and iLOV are identified. Below is an illustration that depicts the transcription start site and the $5^{\prime}$ end of the rose rosette virus and the $3^{\prime}$ end next to the hepatitis delta virus ribozyme cleavage site in the pCB301 plasmid. These three plasmids were delivered by Agrobacterium infiltration into plant leaves. The primary antigenomic transcripts were templates for production of genomic RNA leading to further rounds of replication and transcription. Continued replication results in increasing levels of iLOV expression. B, Microscopic images of iLOV fluorescence in epidermal cells at 2 to 3 days postinoculation (dpi). Mock identifies cells agroinfiltrated to deliver empty vectors. The wild-type RNA1, RNA3, and R5-iLOV minigenome $(\mathrm{R} 1+\mathrm{R} 3+\mathrm{R} 5-\mathrm{iLOV})$ and the replication defective $\mathrm{R} 1_{\mathrm{VAA}}+\mathrm{R} 3+\mathrm{R} 5-$ iLOV are identified below each panel. These mock and $\mathrm{R} 1_{\mathrm{VAA}}$-defective genomes do not produce fluorescence. Scale bars represent $20 \mu \mathrm{m}$. C, Bar graph showing average relative fluorescence per microgram of protein in $N$. benthamiana leaves that were agroinfiltrated with the wild-type R1 or R1 VAA along with R3 and R5-iLOV genome segments. Control leaves were agroinfiltrated to deliver the empty pCB301 vector. Samples were harvested at 3 , 7 , and 13 dpi ( $x$ axis). The fluorometric measures were the averages of three biological replicates and four technical replicates.
(Feng et al. 2019). This virus has three genome segments. The tospovirus L segment encodes the RdRp, the M segment encodes, in ambisense arrangement, the glycoproteins precursor and the cell-to-cell movement protein (MP) (NSm). The S segment is also ambisense arrangement and encodes the $\mathrm{N}$ protein and silencing-suppressor protein (NSs). The TSWV infectious clone consists of three antigenomic cDNAs (agcDNAs) inserted into separate binary plasmids. Additional binary plasmids expressing the RdRp, N, and heterologous viral silencingsuppressor proteins were codelivered with the viral cDNA plasmids to produce active TSWV infection.

Rose rosette virus (RRV) is a negative-strand RNA virus with seven genome segments and belongs to the Emaravirus genus within the family Fimoviridae. RRV has been devastating roses and the rose industry in the United States, causing millions of dollars in losses (Waliczek et al. 2018). RRV infection produces symptoms that include rapid stem elongation, breaking of axillary buds, leaflet deformation and wrinkling, bright red pigmentation, phyllody, and hyper-thorniness (Klemm et al. 2013; Pemberton et al. 2018). RRV accumulates to very low levels, which is why researchers have struggled for several decades to recover virions from infected plants (Laney et al. 2011). The low accumulation likely explains why the RRV genome sequence was only discovered by deep sequencing and contig assembly (Babu et al. 2016; Laney et al. 2011). Because of the large number of genome segments, we wanted to create a system to study virus replication that contained only the minimal number of essential genome segments. Instead of creating a conventional minireplicon system, we report a minigenome system that contains three genome segments as well as a fulllength infectious clone of RRV. We successfully introduced the $i L O V$ fluorescent reporter gene in two locations to study virus accumulation in plant cells.

\section{RESULTS}

The RRV RdRp and N proteins are sufficient for the replication of a template RNA encoding the iLOV protein.

Since there is very little known about the molecular biology of any Emaravirus species, we wanted to assemble the minimal number of genome segments needed to achieve infection in synchronously infected cells while incorporating a reporter gene into the virus genome. We assembled the full-length cDNAs for the agRNA1 (7,026 bp), agRNA3 (1,544 bp), and agRNA5 $(1,665 \mathrm{bp})$ into the pCB301 binary plasmids (Fig. 1A). RRV is a plant virus species in the taxonomic order Bunyavirales and almost all members of this order require the viral $\mathrm{RdRp}$ and $\mathrm{N}$ proteins as the core components for RNA synthesis (Sun et al. 2018). For RRV, $a g R N A 1$ and $a g R N A 3$ encode the predicted RdRp and $\mathrm{N}$ proteins (Table 1). We modified the agRNA5 by replacing the P5 open reading frame with the iLOV coding sequence (335 nt). The agcDNAs were positioned next to the CaMV 35S promoter and HDVrz (Fig. 1A) (Wang et al. 2015).

Agrobacterium cultures harboring agRNA1, agRNA3, and agR5-iLOV plasmids were combined in equal ratios and were infiltrated into Nicotiana benthamiana leaves. At 2 to 3 days postinoculation (dpi), fluorescence was visible throughout the cells using microscopy. The mock-treated leaves showed no fluorescence (Fig. 1B). To determine if the viral RdRp was responsible for iLOV expression, a substitution mutation was engineered into the RNA1 segment to disrupt the catalytic (C) domain of the viral RdRp. The conserved Ser-Asp-Asp tripeptide of the RdRp active site was replaced with Val-Ala-Ala (VAA) to produce RRV RNA1 VAA (Amroun et al. 2017; Gerlach et al. 2015). The RNA1 ${ }_{\text {VAA }}$, RNA3, and RNA5-iLOV were codelivered to $N$. benthamiana leaves and there was no visible iLOV fluorescence (Fig. 1B). 
We quantified iLOV fluorescence in soluble leaf extracts, as a measure of virus gene expression in infected plants. Previous spectroscopic measures of iLOV fluorescence intensity have been reported by expressing proteins in Escherichia coli or cell cultures but not in plants (Chapman et al. 2008; Christie et al. 2012; Mukherjee et al. 2013). First, to determine whether the iLOV fluorescence is the result of direct expression from the $C a M V 35 S$ promoter or genome replication (Fig. 2A), $N$. benthamiana leaves were infiltrated with the replicon, the R5-iLOV construction alone, or agrobacterium harboring an empty vector. Fluorometric analysis of leaf extracts were conducted at 3, 7, and $13 \mathrm{dpi}$, and the relative fluorescence was calculated for each sample and was averaged $(n=5)$ (Fig. 2A). The relative fluorescence (average fluorescence units per microgram of protein) for the replicon was between five- and eightfold higher than the R5-iLOV alone at $3 \mathrm{dpi}$, and all values declined at 7 and 13 dpi. The level of R5-iLOV at 3, 7, and 13 dpi was not greater than the mock control $(P<0.1)$ (Fig. 2A).

Next, we compared the relative fluorescence produced by wild-type and the VAA mutant $\operatorname{RdRp}(n=3)$ (Fig. 2B). At 3 dpi, the fluorescence produced by the wild-type replicon was fourfold higher than the replicon containing RNA $1_{\mathrm{VAA}}$ or mock samples $(P<0.001)$ (Fig. 2B). At $7 \mathrm{dpi}$, the relative fluorescence was almost 10 -fold lower than at $3 \mathrm{dpi}$ and the values were not different between the wild-type and RNA1 $1_{\mathrm{VAA}}$ containing replicons $(P>0.1)$. At $13 \mathrm{dpi}$, fluorescence was barely detectable, suggesting that the replicon is useful for measuring replication activities within the first few days following delivery into leaves. Overall, these experiments suggest that some iLOV expression can be produced directly from the R5-iLOV construction, but iLOV expression is heightened by the activities of the polymerase catalytic domain.

\section{Varying concentrations of the $N$ gene and the use of a silencing-suppressor protein to enhance iLOV expression from the RRV replicon.}

Experiments were conducted to optimize the delivery concentrations for the binary plasmid and to improve fluorescence detection beyond 3 dpi. For the TSWV minireplicon, it was found that altering the concentration of Agrobacterium tumefaciens carrying the $\mathrm{N}$ protein led to increased reporter gene

Table 1. Genome characteristics of rose rosette viruses (RRVs) ${ }^{\mathrm{a}}$

\begin{tabular}{|c|c|c|c|c|}
\hline $\begin{array}{l}\text { RRV genomic } \\
\text { segments }\end{array}$ & $3^{\prime}$ UTR & $\begin{array}{l}\text { Protein amino } \\
\text { acid length }\end{array}$ & $5^{\prime}$ UTR & Potential function $^{b}$ \\
\hline $\begin{array}{l}\text { Segment } 1 \\
(7026 \mathrm{nt})\end{array}$ & 107 & 2,276 & 88 & $\operatorname{RdRp}$ \\
\hline $\begin{array}{c}\text { Segment } 2 \\
(2245 n t)\end{array}$ & 50 & 645 & 257 & Glycoprotein \\
\hline $\begin{array}{r}\text { Segment } 3 \\
(1544 \mathrm{nt})\end{array}$ & 99 & 319 & 494 & Nucleocapsid \\
\hline $\begin{array}{l}\text { Segment } 4 \\
\text { (1541nt) }\end{array}$ & 83 & 361 & 372 & Movement protein \\
\hline $\begin{array}{l}\text { Segment } 5 \\
(1665 \mathrm{nt})\end{array}$ & 61 & 467 & 200 & Unknown function \\
\hline $\begin{array}{r}\text { Segment } 6 \\
(1402 \mathrm{nt})\end{array}$ & 68 & 233 & 631 & Unknown function \\
\hline $\begin{array}{r}\text { Segment } 7 \\
(1649 \mathrm{nt})\end{array}$ & 61 & 465 & 190 & Unknown function ${ }^{\mathrm{c}}$ \\
\hline
\end{tabular}

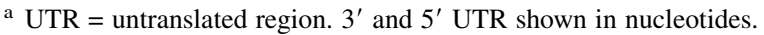

b Protein and domain analysis carried out using InterPro and HMMER (EMBL-EBI) and BLASTP (GENBank). RdRp = RNA-dependent RNApolymerase.

c The high plains wheat mosaic virus (HPWoMV) is also a member of the genus Emaravirus and encodes eight genome segments. RNA7 and RNA8 encode silencing-suppressor proteins (Gupta et al. 2019). RRV encodes seven (not eight) segments. The HPWoMV and RRV P7 proteins share no real sequence conservation to infer similar functions. expression (Feng et al. 2019). For the beet yellows closterovirus and SYNV minireplicon systems, researchers reported adding binary plasmids expressing silencing-suppressor proteins to enhance reporter gene expression (Chiba et al. 2006; Ganesan et al. 2013). In this study, the concentrations of A. tumefaciens delivering agRNA3 used were between an optical density at $600 \mathrm{~nm}\left(\mathrm{OD}_{600}\right)$ of 0.1 to 1.0 , while keeping the $A$. tumefaciens harboring agRNA1 and agR5-iLOV fixed at $\mathrm{OD}_{600} 1.0$ (Fig. 3A). A parallel set of treatments included a binary construct expressing the TBSV P19 virus silencing-suppressor protein. At 5 dpi, we compared the relative fluorescence values obtained at each $\mathrm{OD}_{600}$ concentration to the original $1.0 \mathrm{OD}_{600}$ concentration. In the absence of P19, the average fluorescence for $1.0 \mathrm{OD}_{600}$ was approximately $100 \mathrm{U}$ per microgram of protein and all other $\mathrm{OD}_{600}$ concentrations produced similar average values. When P19 was included, the relative fluorescence increased to $150 \mathrm{U}$ per microgram of protein for $1.0 \mathrm{OD}_{600}$ to between 200 and $250 \mathrm{U}$ per microgram of protein for all other $\mathrm{OD}_{600}$ concentrations, indicating a positive effect of P19 at lower $\mathrm{OD}_{600}$ concentrations $(P<0.1)$ (Fig. 3A). At 7 dpi, the fluorescence at $1.0 \mathrm{OD}_{600}$ remained around $100 \mathrm{U} / \mu \mathrm{g}$ and increased toward $175 \mathrm{U} / \mu \mathrm{g}$ at the lower $\mathrm{OD}_{600} 0.1$, although the increase was not significant $(P>0.1)$ (Fig. 3A). When we added $\mathrm{P} 19$, the relative fluorescence values at 7 dpi for $\mathrm{OD}_{600}$

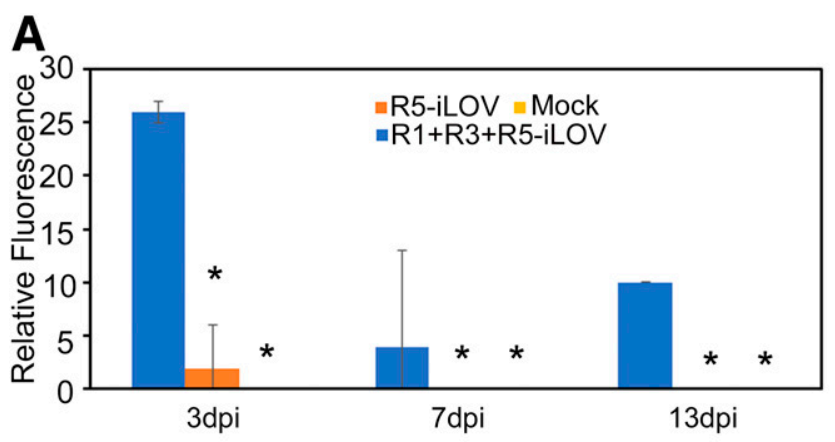

B

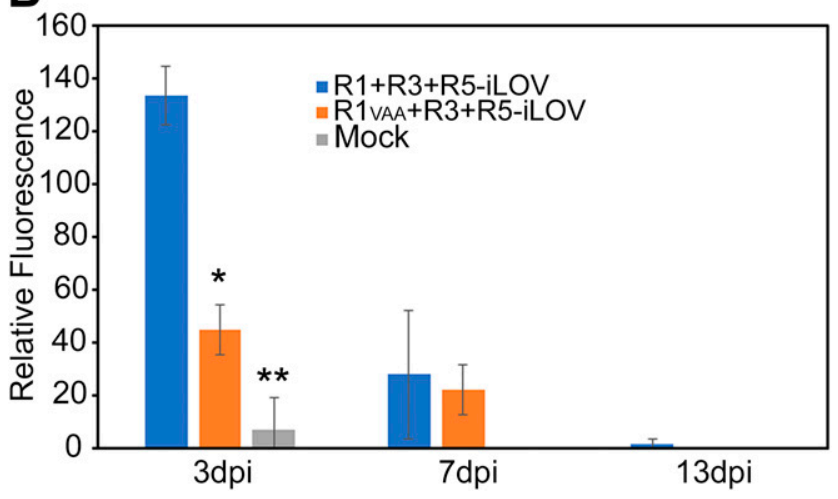

Fig. 2. Fluorometric units reported at 3, 7, and 13 days postinoculation (dpi) following agro-delivery of constructs. A, Relative fluorescence levels in leaves treated with the replicon, R5-iLOV alone, or R5-iLOV and TBSV P19. The average fluorescence values were normalized to the samples treated with the plasmid backbone without iLOV (Mock) at each timepoint. The values among different treatments were compared using analysis of variance to obtain a significant $F$ ratio and $P$ value at each timepoint. Then, a $t$ test was conducted for all sample values compared with the replicon. Asterisks identify treatments that differ from the replicon $(P<0.1)$. B, Relative fluorescence in leaves expressing the wild-type $\mathrm{R} 1$ or $\mathrm{R} 1_{\mathrm{VAA}}$ plus R3 and R5-iLOV or pCB301 backbone without iLOV (Mock). The relative fluorescence levels were obtained by subtracting fluorescence values representing the untreated sample controls. Homogenates here were prepared using phosphate buffered saline. A two-tailed independent sample $t$ test was conducted. The wild-type replicon and the replicon containing $\mathrm{R} 1_{\mathrm{VAA}}$ were significantly different from each other at 3 and 13 dpi $(P>0.05)$. 
1.0 and 0.7 remained elevated but were lower for treatments involving $\mathrm{OD}_{600} 0.5,0.3$, and 0.1 .

Next, we compared the relative fluorescence values at 3, 5, and 7 dpi for delivery of agRNA1, agRNA3, agR5-iLOV, and $\mathrm{P} 19$, using different $\mathrm{OD}_{600}$ concentrations for agRNA3 (Fig. 3B). The relative fluorescence was higher at $3 \mathrm{dpi}$ when the levels of agRNA3 were below $\mathrm{OD}_{600}$ 1.0. For treatments involving agRNA3 at $\mathrm{OD}_{600}$ of 0.3 and 0.1 , the values were higher at 3 and 5 dpi than the $\mathrm{OD}_{600}$ of 1.0 , but these values sharply declined at $7 \mathrm{dpi}$. For $\mathrm{OD}_{600} 0.7$ plus the TBSV P19, the fluorescence remained at the same levels at 5 and 7 dpi.

\section{The RRV infectious clone produces systemic infection in $N$. benthamiana plants.}

There are reports that RRV is transmissible by mites and by grafting in roses but there are no reports of mechanical inoculation to any plants (Di Bello et al. 2018; Shires et al. 2019). To first demonstrate mechanical inoculation of RRV, we used sap from an infected rose plant to rub-inoculate a set of $N$. benthamiana plants. At 25 dpi, reverse transcription (RT)-PCR was conducted using diagnostic primers (the agRRV4-F1 and agRRV4-R1 primer pair) (Supplementary Table S1) that amplify sequences of RNA4 and confirmed $100 \%$ of the plants were systemically infected (Table 2) (Di Bello et al. 2018). Plants treated with buffer alone were negative for RRV infection (Table 2). Based on these results, we hypothesized that we successfully delivered RRV by mechanical inoculation using a full-length infectious clone.

We prepared a full-length infectious system containing all RRV segments (Fig. 4A) (Wang et al. 2015). We hypothesized that the viral RdRp (RNA1), glycoprotein (RNA2), N (RNA3), and MP (RNA4) represent the minimum requirement for systemic infection. The hypothesis that RNA4 encodes the viral MP is based on significant protein homology with the raspberry leaf blotch virus (an emaravirus) $\mathrm{P} 4$ protein that was reported to be the viral MP (Table 1) (Yu et al. 2013). Agrobacterium cultures containing plasmids encoding RRV RNAs 1 through 4 (RRV1-4) were combined in equal ratios and were then infiltrated to young $N$. benthamiana leaves. The RRV1-4 system lacked the iLOV reporter. The mock-inoculated samples were treated with A. tumefaciens containing the backbone binary vector. Systemic leaf-yellowing symptoms appeared after three weeks of infection while mock-treated leaves remained green (Fig. 4B and C). Total RNA was extracted from systemic leaves at $25 \mathrm{dpi}$, and RT-PCR confirmed that approximately $89 \%$ (16 of 18) of the RRV1-4 inoculated plants were systemically infected (Table 2). Then, RT-PCR was carried out to verify each RNA segment (primers are listed in Supplementary Table S1) succeeded to spread into the upper leaves (Fig. 4D). As a positive control, RT-PCR analysis was carried out using total RNA from a garden-infected rose bush. PCR products representing RNA1 through RNA7 were recovered from infected roses. For samples inoculated with the infectious clone RRV14, PCR products representing only RNA segments 1 through 4 , but not segments 5 through 7 (as expected) were detected in each $N$. benthamiana sample (Fig. 4D). All PCR products were sequenced to verify they originated from RRV.

Since RRV has been reported to produce double-strand RNA (dsRNA) in infected Rosa multiflora plants and this has been used in the past as diagnostic evidence of infection (Di et al. 1990), we carried out reverse transcription RNase protection
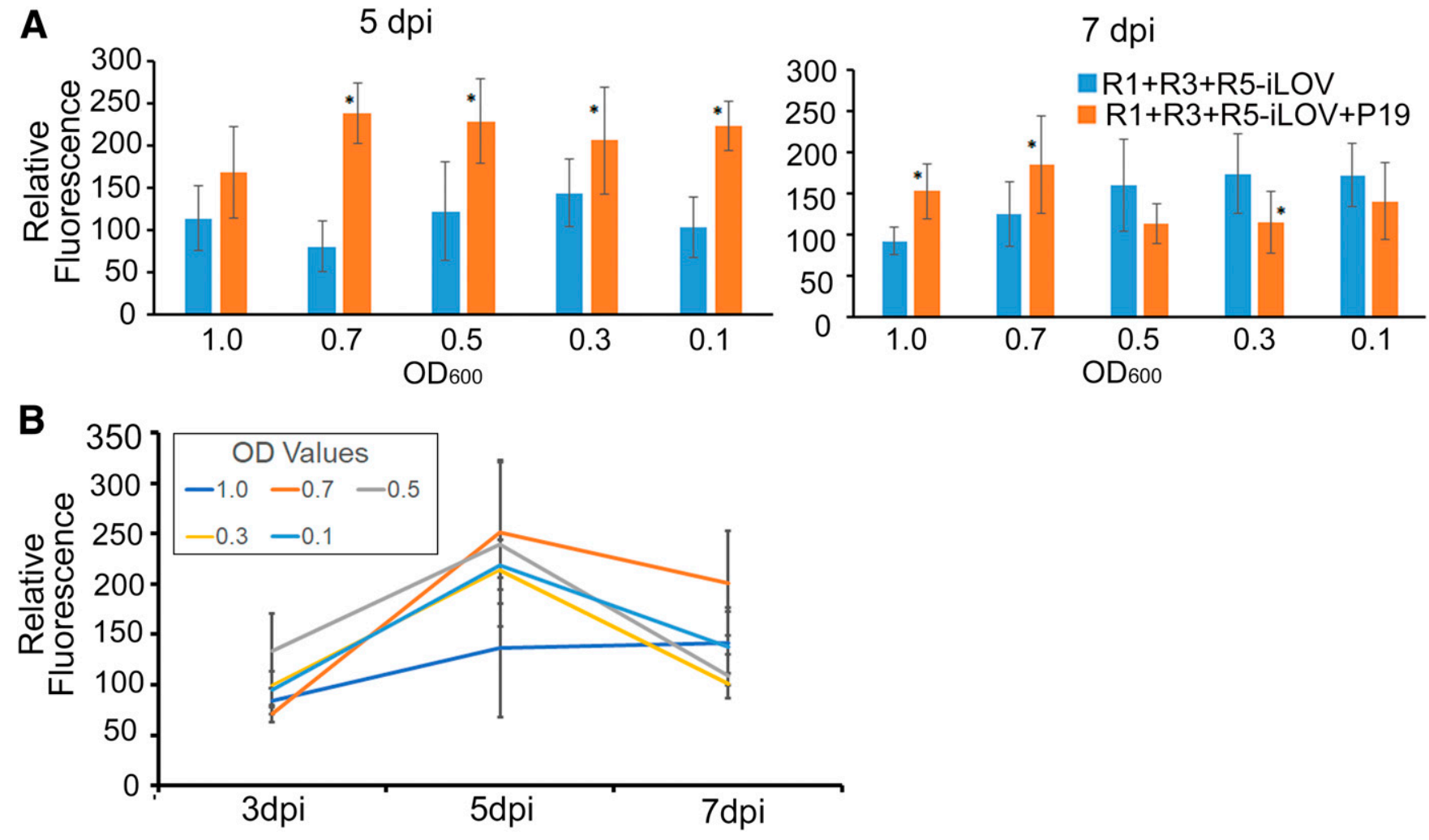

Fig. 3. Delivery of antigenomic (ag)RNA1, agRNA3, agRNA5, and P19 to Nicotiana benthamiana leaves. The optical density at $600 \mathrm{~nm}\left(\mathrm{OD}_{600}\right)$ concentrations of agRNA3 were varied while agRNA1, agR5-iLOV, and P19 were kept fixed at $\mathrm{OD}_{600}=1.0$. All relative fluorescence values are the averages of fluorescent units per microgram of protein of three biological replicates and four technical replicates. A, Blue bars represent the average fluorescence units per microgram of protein of samples expressing R1+R3+R5-iLOV. The orange bars represent the average values of samples expressing R1+R3+R5-iLOV+P19. The bar graph on the left represents values obtained at 5 days postinoculation (dpi) and the bar graph on the right represents 7 dpi. The $x$ axis identifies the $\mathrm{OD}_{600}$ values for delivery of agRNA3. Each asterisk shows the results of $t$ test analysis identifying significant differences between samples with and without the addition of $\mathrm{P} 19$ for each concentration $(0.5 \leq P \leq 0.1)$. B, The relative fluorescence between 3,5 , and 7 dpi in samples expressing R1+R3+R5-iLOV+P19. Each colored line represents values for various $\mathrm{OD}_{600}$ concentrations of agrobacterium delivering agRNA3. 
assays (RT-RPA) using two samples of RRV1-4 infected plants (Fig. 4E). This method is reported to be more sensitive than Northern blotting and detects low-copy RNAs (Li et al. 2018). Here, RT-PCR amplification was carried out to detect RNA segments 1 through 4, using gene-specific primer sets (Supplementary Table S1). Products were analyzed by $1.2 \%$ agarose gel electrophoresis. Amplicons ranging from 500 to $585 \mathrm{bp}$ were generated that represented the dsRNA1, dsRNA2, dsRNA3, and dsRNA4 in infected $N$. benthamiana plants but not in the mock-treated plants (Fig. 4E). RNA from infected rose plants produced similar RNA1, RNA2, RNA3, and RNA4 amplicons, while none were detected in healthy rose samples.

Next, to determine if the construction of all seven segments could be combined to produce systemic infection, we inoculated $N$. benthamiana plants with RRV1-7 and, at $25 \mathrm{dpi}$, approximately $94 \%$ of the plants were infected, as determined by diagnostic RT-PCR (Table 2). Then, for comparison, we inoculated a set of plants with RRV1-4 and a set with RRV1-7 simultaneously. While the RRV1-4 plants showed more yellowing in the older leaves than the RRV1-7 plants, the symptoms in the upper leaves were similarly mild (Fig. 5A). Multiplex RT-PCR detection of all genome segments was carried out as reported by Babu et al. (2016). The attB-RRV-F/R primer set recognizes the conserved $5^{\prime}$ and $3^{\prime}$ sequences and, as expected, yielded fulllength amplicons of RRV1-4 and RRV1-7 (Babu et al. 2016) (Fig. 5B). Notably, PCR products detecting RNA3 through RNA7 comigrate on a $1.2 \%$ agarose gel. In addition, there were intermediate size amplicons of 1.8 and $2.0 \mathrm{~kb}$, which are likely derivatives of RNA2 as reported previously (Babu et al. 2016).

\section{Insertion of the iLOV reporter into two locations in the RRV genome to track systemic infection in whole plants.}

The infectious clone system RRV-7R5-iLOV is comprised of binary plasmids encoding the seven segments, and the wildtype RNA5 construct was replaced with the R5-iLOV construct (Fig. 6A). The upper leaves were examined using epifluorescence microscopy to detect iLOV fluorescence at $13 \mathrm{dpi}$ and $100 \%$ of the plants were systemically infected (Fig. 6A; Table 2). At $25 \mathrm{dpi}$, the inoculated plants showed systemic mottling and necrosis (Fig. 6A).

It is possible that relocating iLOV to another genome segment will improve its expression. Therefore, we introduced iLOV to the $3^{\prime}$ end of the glycoprotein gene in RNA2 (named R2-iLOV) (Fig. 6B). N. benthamiana plants were inoculated with the RRV-4R2-iLOV, which encodes the first four RNA segments, and the RRV-7R2-iLOV, which is comprised of all seven segments. After 3 weeks, the infected plants showed yellow mottling symptoms and wilting of the upper leaves, as compared with the control (Fig. 6B). For RRV-4R2-iLOV and -7R2-iLOV, fluorescence was detected in systemic leaves at 13 dpi using epifluorescence microscopy (Fig. 6B) but not using a hand-held UV lamp. One hundred percent of the plants became infected, indicating that iLOV was not disruptive when it was inserted into either location of the viral genome.

Systemic infection was also confirmed using diagnostic RTPCR detecting RNA4 (Fig. 6C) (Di Bello et al. 2018). We conducted additional RT-PCR to detect each genome segment in samples taken from the upper leaves at $25 \mathrm{dpi}$ and a subset of those samples is represented in Figure 6D. All PCR products were sequenced to confirm they originated from the RRV genome. To verify the iLOV coding sequence is stably maintained in the systemic leaves, we carried out RT-PCR, using primers (agRRV2-F1 and R2-iLOV-R) to amplify a 1,080-bp product for RNA2 that overlaps the glycoprotein-iLOV fusion and another primer pair (IF-agR5-F and R2-iLOV-R) to amplify a 433-bp product that overlaps the iLOV and untranslated region (UTR) in RNA5 (Fig. 6D).

\section{Inoculation using RRV infectious clone to rose plants.}

We inoculated the RRV1-7 infectious clone to roses to determine if the full-length infectious clone produces systemic infection in its natural host. For this, we compared the symptoms and timing of infection between plants inoculated with leaf sap from an RRV-infected plant and agro-delivery of the RRV1-7 clone, which did not contain the iLOV reporter. We chose to inoculate rose plants that were at the same developmental stage. Roses are vegetatively propagated plants, and we selected individual plants that were anatomically similar, meaning that they all had three canes that branched to secondary stems and there were compound leaves on both the canes and secondary stems. All plants were similar in height, 12 inches from the surface of the pot (Fig. 7A). The sap inoculum and the RRV1-7 infectious clone were applied using an artist airbrush (Fig. 7A) to compound leaves of a single secondary stem of one cane. The inoculated secondary stem was surrounded by a shield to focus the airbrush delivery and not contaminate other canes. We then sampled noninoculated leaves for evidence of virus spread throughout the plant. Virus-infected plants were monitored in the greenhouse for 60 days and showed yellow mottling symptoms (Fig. 7C and D). We harvested one new emerging leaf from the inoculated cane and the noninoculated cane and conducted diagnostic RT-PCR, using the RRV4-F1 and RRV4-R1 primer pair to verify infection (Fig. 7E; Supplementary Table S1). All samples tested positive by RT-PCR for RRV infection, indicating that $100 \%$ of the rose plants became systemically infected following inoculation with sap or the infectious clone. Additional RT-PCRs were carried out to verify the presence of each RNA segment in the systemic leaves (Fig. 7F; Table 2).

Cytopathic alterations that are associated with RRV have been reported previously (Di et al. 1990; Mielke-Ehret and Mühlbach 2012). Typically, VLPs of 110 to $180 \mathrm{~nm}$ in diameter accumulate near Golgi, microbodies, and chloroplasts (Silvestro and Chapman 2004). We expect that, if RRV had spread systemically in the rose plants that tested positive by RT-PCR, we would see VLPs and other cellular perturbations associated with infection using electron microscopy. Leaf segments were collected from the inoculated plants and positive control samples were collected from infected garden rose leaves. Ultrathin sections of buffer (Mock)-treated leaves (Fig. 7G), infected garden rose leaves (Fig. 7H), sap-infected rose leaves (Fig. 7I), and RRV1-7-infected leaves (Fig. 7J) were prepared and stained with uranyl acetate and lead citrate, and all cells were well-preserved. The infected cells showed similar electrondense spheres that resembled VLPs and these were not present in healthy tissues (Fig. 7G). We also observed other kinds of membraneous aggregates (Fig. 7H1 and $\mathrm{H} 2$ ) that were not present in healthy cells, which may be additional cytological

Table 2. Total proportion of systemically infected plants confirmed by RTPCR using the agRRV4 F1/R1 primer set ${ }^{\mathrm{a}}$

\begin{tabular}{lc}
\hline Constructs & N. benthamiana \\
\hline Rose sap inoculum & $12 / 12$ \\
Buffer treated & $0 / 8$ \\
pCB301 & $0 / 12$ \\
RRV1-4 & $16 / 18$ \\
RRV1-7 & $17 / 18$ \\
7R5-iLOV & $8 / 8$ \\
4R2-iLOV & $8 / 8$ \\
7R2-iLOV & $8 / 8$ \\
\hline
\end{tabular}

a The proportions of infected Nicotiana benthamiana were pooled from two experiments. All plants were assayed by reverse transcription (RT)-PCR at 25 days postinoculation. 
features of disease, as reported in early studies of rose rosette disease (Ishikawa et al. 2015; Mielke-Ehret and Mühlbach 2012).

\section{DISCUSSION}

This study reports an unconventional minireplicon system and a conventional infectious clone system for RRV and represents the first such system for a member of the genus Emaravirus. This study established a minigenome replication system for RRV based on the reconstitution of the gRNA1, gRNA3, and a modified gRNA5 containing the iLOV coding sequence. The viral RdRP and $\mathrm{N}$ are generated from the HDVrz-processed transcripts rather than standard expression vectors used in conventional minireplicon systems developed for plant rhabdoviruses and tospoviruses, in which the replicase genes are overexpressed from CaMV 35S promoters (Feng et al. 2019; Wang et al. 2015). While a conventional replicon system provides the viral $\mathrm{RdRp}$ and $\mathrm{N}$ proteins in trans by overexpression from a CaMV $35 \mathrm{~S}$ promoter to mediate replication of a templated minigenome, this system produces the viral RdRp and $\mathrm{N}$ proteins as part of a tripartite minigenome construction (Laney et al. 2011; Mielke-Ehret and Mühlbach 2012). This RRV minigenome system will enable studies of the minimal requirements for virus infection and host responses when virus replication is occurring at natural levels. Such a system will also be valuable for host transcriptome studies because these viral genes are not overexpressed, which could potentially exacerbate host responses to infection. When using a conventional replicon that overexpresses the viral $\mathrm{RdRp}$ and $\mathrm{N}$ proteins, a transcriptome study will report the host responses that are influenced by the overexpression as well as responses to infection. Having created a system that contains the minimal number of segments to achieve virus infection, we can conduct transcriptome studies to identify subtle host transcriptional changes, which could include factors that are incorporated into the viral replication machinery (Verchot 2012, 2016; Williams et al. 2014). Using a replicon system that overexpresses viral proteins is more likely to produce a transcriptome dataset that includes exacerbated levels of certain defense transcripts or other stress-response genes that may be necessary to accommodate the synthesis of foreign proteins.

RRV belongs to the order Bunyavirales, and most bunyaviruses consist of three single-stranded RNA segments of negative or ambisense polarity. The UTRs on the $3^{\prime}$ and $5^{\prime}$ ends serve as promoters for transcription and replication and mediate packaging of genome segments into virus particles. The mRNA synthesis for most bunyaviruses is initiated with capped oligonucleotides cleaved from host cell mRNAs by the endonuclease activity of the RdRp (Hopkins et al. 2013; Ma et al. 2019; Sun et al. 2018; Walia and Falk 2012). This RRV minireplicon system will be useful to investigate the RNA synthesis activity of the viral RdRp and contributing features of UTRs for these three genome segments. Key mutations can easily be introduced into the $\mathrm{RdRp}$ and $\mathrm{N}$ proteins to dissect their functions during infection and to selectively study parts of the emaravirus replication cycle (Amroun et al. 2017; Gerlach et al. 2015). Notably, by generating natural levels of RdRp and $\mathrm{N}$ proteins rather than overexpressing these proteins from the CaMV 35S promoter, the level of iLOV accumulation was too low to detect by a hand-held UV lamp but was clearly distinguishable in the cells containing the replicon from mocktreated cells using microscopy. Visible iLOV expression was also eliminated by introducing a VAA mutation into the catalytic domain of the viral RdRp, suggesting that iLOV expression was dependent upon the RNA synthesis abilities of the viral RdRp. These studies also demonstrate that fluorometry can be used to study iLOV expression in plants, which has not been reported before. The fluorometric analysis was also effective for measuring iLOV expression of the minireplicon at $3 \mathrm{dpi}$.

Notably, the VAA substitution mutation in the $\mathrm{C}$ domain of the RdRp was not sufficient to completely eliminate evidence of virus replication (Fig. 2B). These data suggest that there are likely multiple domain elements that drive polymerase activity. Since the replicon measures expression of fluorescence from the R5-iLOV template, it is possible that the RdRp or N protein might be multifunctional, with additional silencing-suppressor activities that enhance iLOV expression from the binary construct. For example, the tobacco mosaic virus P126 protein provides methyl transferase and helicase activity that is essential for virus replication. The methyl transferase and helicase domains and another nonconserved domain II were shown to independently contribute activities to suppress host silencing, although their mechanistic actions are not known (Ding et al. 2004; Wang et al. 2012). The cytorhabdovirus $P$ protein that is a cofactor for the viral polymerase is also a silencingsuppressor protein (Mann et al. 2015). In addition, the carmovirus coat protein $(\mathrm{CP})$ is required for genome encapsidation and binds small RNA to suppress RNA silencing. The carmovirus $\mathrm{CP}$ has a glycine-tryptophan motif that is found in many silencing-suppressor proteins, including the high plains wheat mosaic virus (an emaravirus) P7 and P8 proteins. We analyzed amino acid sequences of the RRV replicon proteins as well as the P7 protein and failed to identify a glycine-tryptophan motif or homology with the HPWMV silencing-suppressor protein (Cao et al. 2010; Genovés et al. 2010; Gupta et al. 2019; Weber and Bujarski 2015).

This study also demonstrated that the addition of the TBSV P19 silencing-suppressor protein increased iLOV expression in the minireplicon system. Considering the replicon systems for TSWV and SYNV, in which three viral silencing-suppressor proteins were required to suppress host antiviral defenses and to ensure visible GFP expression in systemic tissues (Feng et al. 2019; Ganesan et al. 2013; Qian et al. 2017), it was surprising to see that the inclusion of a heterologous silencing-suppressor protein was not essential to establish infection, although it did serve to enhance iLOV expression.

RRV accumulates to very low levels, which explains why we failed to detect all viral genome segments using Northern analysis (data not shown). Low accumulation levels can also explain why iLOV was only visible using microscopy or sensitive spectrophotometry. The iLOV factor derives from a plant blue-light receptor that is induced by UV-A/blue light to covalently bind to the flavin mononucleotide (FMN) chromophore (Christie et al. 2012; Davari et al. 2016). Fluorescence is the result of photoexcitation and covalent FMN binding. We selected iLOV for this study because of prior success incorporating this reporter into a plant virus genome (Chapman et al. 2008). Studies also demonstrated that iLOV can be targeted to other locations in the cell without compromising fluorescence. For example, the inclusion of the endoplasmic reticulum (ER) or Golgi signal peptide, revealed that fluorescent iLOV protein could be targeted to the lumen of the ER or the trans face of the Golgi apparatus and retain its characteristic fluorescence (Davari et al. 2016). The fusion of iLOV to the C terminus of Arabidopsis histone 2B also produced distinct labeling of the nucleus and nucleolus, providing further evidence that the requirement for FMN does not limit the utility of iLOV for these subcellular compartments (Christie et al. 2012; Davari et al. 2016; Mukherjee et al. 2013). It is possible that iLOV fluorescence may be impaired by RRV infection, making it a less than ideal reporter gene. The cytopathology caused by RRV infection could interfere with proper folding of iLOV or covalent linkage with FMN. Further experiments comparing different reporter genes and introducing the reporter into 

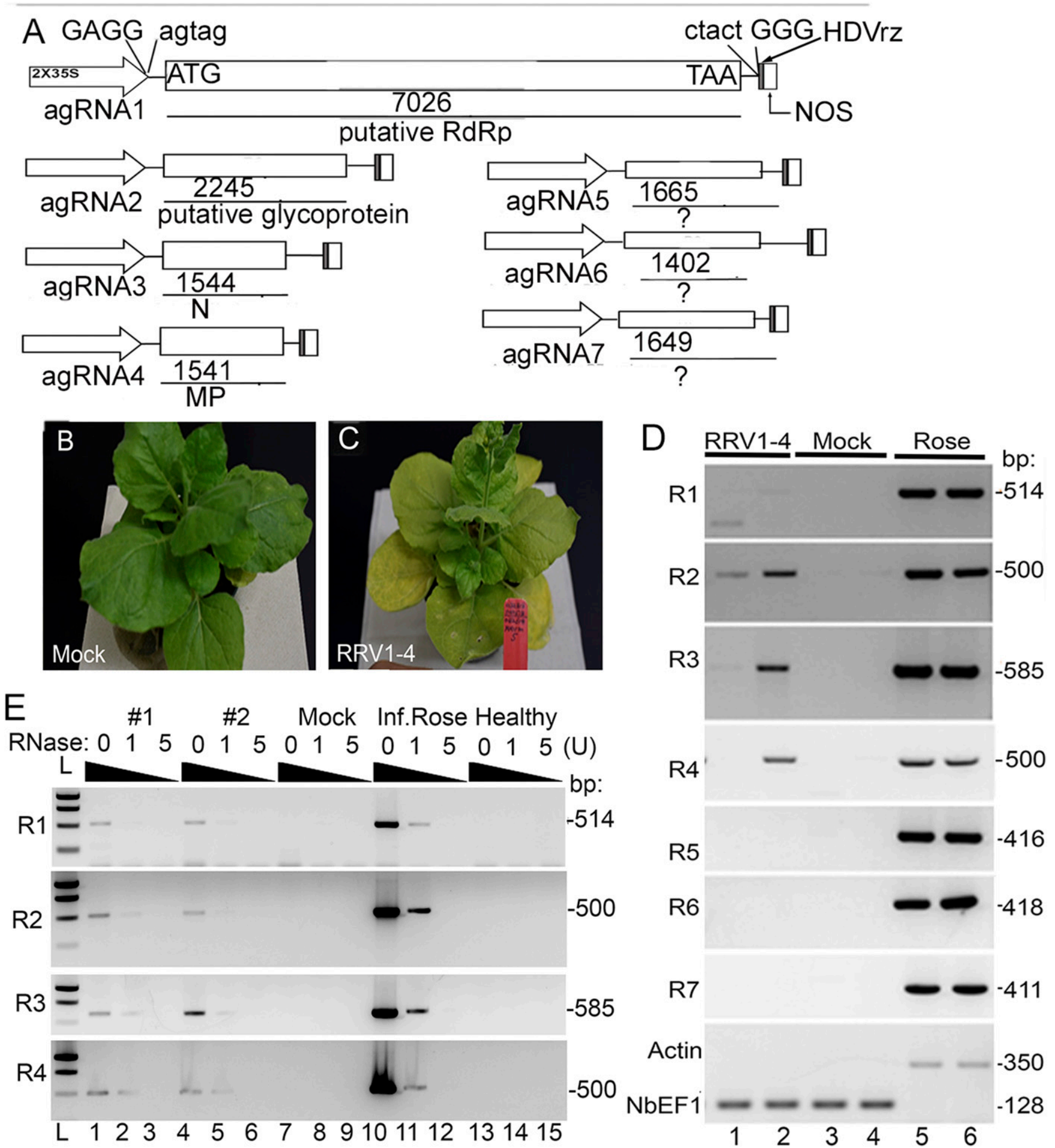

Fig. 4. Nicotiana benthamiana infected with the infectious clone RRV1-4. A, Diagrammatic representation of the infectious clone. Open arrows indicate the duplicated $35 \mathrm{~S}$ promoter. Adjacent sequence directly fusing the $5^{\prime}$ end of the antigenomic cDNA to the promoter is highlighted above the arrow. Each open box represents the open reading frame and is identified as the putative viral RNA-dependent RNA polymerase (RdRp), glycoprotein, nucleocapsid (N), movement protein (MP), and unknown (?) proteins. The C-terminal sequence fused to the hepatitis delta virus ribozyme and nos terminator is indicated. The nucleotide length of each cDNA is provided below the boxes. B and C, Mock-treated and RRV1-4 infected plants at 25 days postinoculation (dpi). D, Reverse transcription (RT)-PCR verified the accumulation of RNA1 through RNA4 in two samples of $N$. benthamiana (lanes 1 and 2 ) and control rose samples (lanes 5 and 6 ). Two mock control samples were included (lanes 3 and 4). RNA segments are identified on the left. The amplicon sizes are defined on the right of each ethidium bromide-stained $1.2 \%$ agarose gel. As an internal control to demonstrate that equal amounts of RNA were used for RT-PCR analysis, RT-PCR was carried out using primers to detect EF1 in N. benthamiana leaves and actin in rose. E, Reverse transcription RNAse protection detecting double-stranded RNase. Treatment with 0,1 , and $5 \mathrm{U}$ of RNase I is identified at the top. RT-PCR products were analyzed by $1.2 \%$ agarose gel electrophoresis. RNAs 1 through 4 are identified on the left, and the sizes of each amplicon is indicated on the right. $\mathrm{L}=1-\mathrm{kb}$ ladder. 
different genome locations will be needed to enhance visible gene expression.

A full-length infectious clone system was constructed of seven binary plasmids encoding the agRNA for each viral segment. First, experiments were conducted to determine if RNA segments 1 through 4 were enough to combine and produce systemic infection. This experiment was carried out because the first reported genome sequence for RRV identified only four RNA segments in wild Rosa multiflora plants. The additional segments, RNA5 through RNA7 were discovered later in commercial roses, and this initial observation suggested the possibility that infection may not require the additional RNAs (RNA5 through RNA7) (Babu et al. 2016; Di Bello et al. 2015; Laney et al. 2011). Inoculation of $N$. benthamiana plants with RRV1-4 and RRV1-7 produced systemic infection with high efficiency, between 88 and $100 \%$ of the inoculated $N$. benthamiana and rose plants developing systemic symptoms (Supplementary Table S1). Since there was difficulty to detect viral genomic RNA by Northern analysis, this study used two RT-PCR-based assays that would detect viral agRNA and mRNAs. First, a standard diagnostic RT-PCR assay that detects RNA4 has been reported and is routinely used by university plant diagnostic labs (Di Bello et al. 2018). Using similar primers to detect segment 4 RNAs, produced evidence of high infection rate from the infectious clone. Second, a multiplex detection system that detects all RNA segments using primers that detect conserved UTRs of the viral RNAs was also recommended in the literature (Babu et al. 2017). Similar primers were used in this study, producing further evidence of systemic virus accumulation in
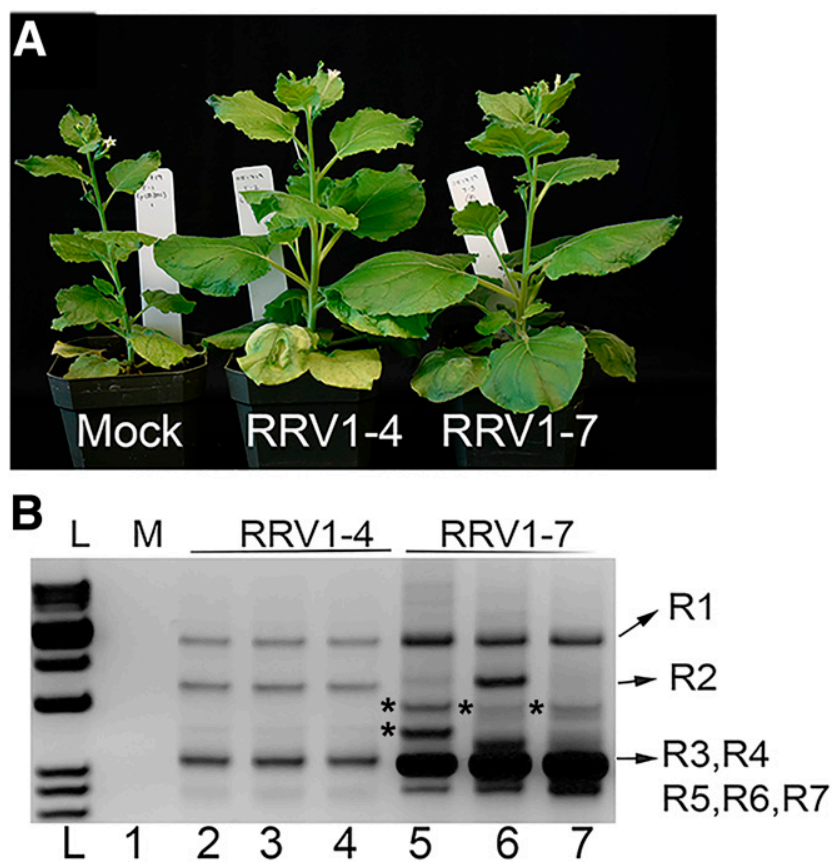

Fig. 5. Nicotiana benthamiana infected with the infectious clone RRV1-4 or RRV1-7. A, Mock-treated, RRV1-4-, and RRV1-7-infected plants at 25 days postinoculation (dpi). The virus-infected plants were larger and had wider leaves. The oldest RRV1-4 leaves at the bottom of the plant were yellowed and wilted. The upper leaves of RRV1-4 or RRV1-7 infected plants show mild or no symptoms. B, Multiplex reverse transcription-PCR using RNA samples from mock-treated plants (M, lane 1) and plants infected with either RRV1-4 (lanes 2 to 4) or RRV1-7 (lanes 5 to 7). Amplicons representing each RNA 1 through 7 are identified on the right. The arrows point to individual RNA1, RNA2, and aggregate bands RNAs37, which comigrate on a gel. Asterisks (*) identify intermediate size amplicons, as reported in Babu et al. (2016). most of the inoculated plants. Finally, RT-RPA was carried out to detect the replicative RNA forms (Li et al. 2018).

$\mathrm{RRV}$ is the most devastating viral disease of roses in North America (Pemberton et al. 2018). The disease and its symptoms were described in the 1940s, and it was first described as a virus with a negative-sense RNA genome in 2011 (Laney et al. 2011). Initially, RRV was reported to have four genome segments. Later RNA5, RNA6, and RNA7 were identified and their sequences were published (Babu et al. 2016). This study also demonstrated that the infectious clone could be used to infect the natural host as well as a laboratory experimental host that is already known to be highly susceptible to a wide range of plant viruses. Using an artist airbrush for delivery of the infectious clone, RRV appeared systemically in rose within 60 days of inoculation. This observation is intriguing new information because, until now, the time from inoculation to the onset of systemic infection and the appearance of disease symptoms has not been known. This new infectious clone technology will enable investigations into virus-host interactions in roses as well as the laboratory host $N$. benthamiana.

In summary, we established a new minireplicon and infectious clone for the recovery of RRV from infected plants. This is the first such systems for a plant-infecting, multicomponent, negative-strand RNA virus. This technology can be used for reverse genetic studies to understand the fundamental aspects of RRV biology. We anticipate that this technology opens the possibility to engineer similar reverse genetic systems for other Emaravirus species.

\section{MATERIALS AND METHODS}

\section{Bioinformatic analyses.}

Protein sequences of viruses were retrieved from the National Center for Biotechnology Information (NCBI) protein archive. Protein and domain analyses were carried out using InterPro and HMMER (EMBL-EBI), BLASTP (NCBI), and manually (Altschul et al. 1990; Mitchell et al. 2019; Potter et al. 2018).

\section{Construction of RRV minireplicon and infectious clone systems.}

The full-length cDNAs for agRNA1 (7,026 bp), agRNA2 (,2245 bp), agRNA3 (1,544 bp), and agRNA4 (1,541 bp) were synthesized de novo (NCBI reference sequences NC_015298.1, NC_015299.1, NC_015300.1, and NC_015301.1) by GenScript. The cDNAs were inserted into the small binary plasmid pCB301-HDV between the double CaMV 35S promoter and the HDV antigenomic ribozyme and Nos terminator (Wang et al. 2015). Plasmids were named pCB301-agRNA1, pCB301agRNA2, pCB301-agRNA3, and pCB301-agRNA4. The pCB301-HDV plasmid is a binary plasmid with a duplicated CaMV 35S promoter and 3' HDVrz sequence, which was provided by Z. Li (Zhejiang University, Hangzhou, China). The full-length agRNA segments 5, 6, and 7 (MN095111, MN095112, MN095113) were amplified by RT-PCR prepared from infected rose leaves (variety Julia Child), using the following primer pairs: IF-agR5-F/R, IF-agR6-F/R, and IF-agR7-F/R, with $15 \mathrm{nt}$ that overlap vector sequences. The cDNA was positioned next to the CaMV 35S promoter and HDVrz to produce viral transcripts with authentic ends. To prepare pCB301-R2 iLOV and pCB301-R5 iLOV constructs, the primers of R2-iLOV-F/R with pCB301-R2-F/R and R5-iLOV-F/R with pCB301-R5-F/R (Supplementary Table S1) were used to amplify iLOV fragments from TMV_iLOV (Chapman et al. 2008) and fragments of pCB301_R2 and pCB301_R5. All PCRs were carried out using high-fidelity $2 \times$ Platinum SuperFi Green PCR master mix 
(Invitrogen). The high-fidelity directional In-Fusion HD cloning kit (Takara Bio USA, Inc.) was used to introduce each amplified full-length cDNA into the pCB301-HDV. All constructs were confirmed by sequencing before being transformed into A. tumefaciens GV3101.

\section{Plant materials and virus inoculation.}

Nicotiana benthamiana plants were grown at $23^{\circ} \mathrm{C}$ with a 16 h-day and 8-h-night photoperiod in a growth chamber. Commercial rose plants were grown in a greenhouse with temperature set to $23^{\circ} \mathrm{C}$. Three-week-old plants were inoculated with extracts taken from RRV-infected rose plants (variety Julia Child). Plant extracts were prepared by grinding $0.5 \mathrm{~g}$ of infected leaves in $15 \mathrm{ml}(1: 30 \mathrm{wt} / \mathrm{vol})$ of $0.05 \mathrm{M}$ phosphate buffer $(\mathrm{pH} \mathrm{7.0)}$ and filtering through cheesecloth. Then SUPERaseIn RNase inhibitor (Invitrogen) $(1 \mathrm{U} / \mathrm{ml})$ and $0.1 \%$ volume of Silwet-L77 were added to the extract and were loaded to the reservoir of an artist airbrush. Plants were lightly dusted with Carborundum. Extracted leaf homogenate was applied using the Central Pneumatic 3/4 a 3 oz airbrush kit (Harbor Freight) (Fig. 1A).
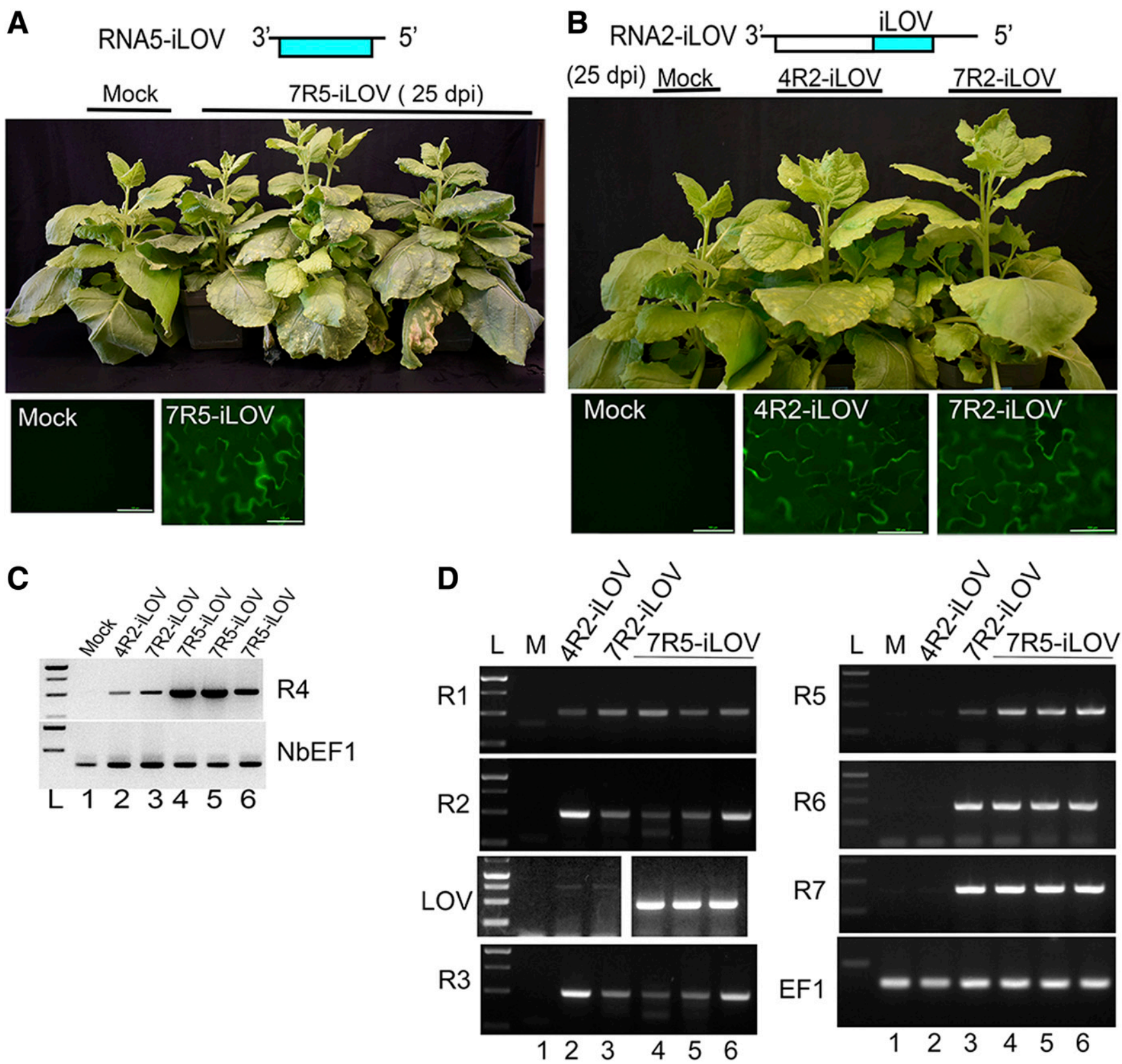

Fig. 6. Nicotiana benthamiana infected with rose rosette virus (RRV) containing iLOV in two different genome locations. For reverse transcription (RT)-PCR $E F-1$ is an internal control showing equal loading in each lane. $\mathrm{L}=1-\mathrm{kb}$ ladder. A, R5-iLOV construction. Plants were inoculated with RRV 7R5-iLOV and show severe symptoms at 25 days postinoculation (dpi). Epifluorescence microscope images of infected leaf epidermal cells at $13 \mathrm{dpi}$. Bars $=100 \mu \mathrm{m}$. B, iLOV is fused to the glycoprotein precursor. Plants were inoculated with RRV 4R2-iLOV or 7R2-iLOV and showed systemic mosaic symptoms. Epifluorescence microscope images of infected leaf epidermal cells at $13 \mathrm{dpi}$. Bars $=100 \mu \mathrm{m}$. C, A representative $1 \%$ agarose gel shows RT-PCR products obtained from infected plants, using diagnostic primers agRRV4-F1 and agRRV4-R1. The identity of each sample is listed above each lane. These diagnostic primers were used to initially confirm that the plants were systemically infected at $25 \mathrm{dpi}$. D, The $1 \%$ agarose gel containing RT-PCR products detecting each RRV genome segment in the upper leaves of symptomatic plants at 25 dpi. The agRRV2-F1 and R2-iLOV-R primers were used to amplify a 1,080-bp product for RNA2 that overlaps the glycoprotein-iLOV fusion. The IF-agR5-F and iLOV-R primers were used to amplify 433 bp that overlaps iLOV and the viral untranslated region. 
A

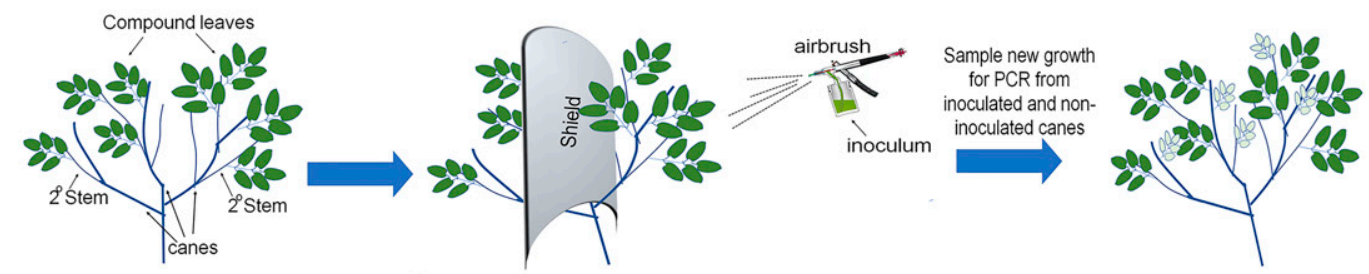

B
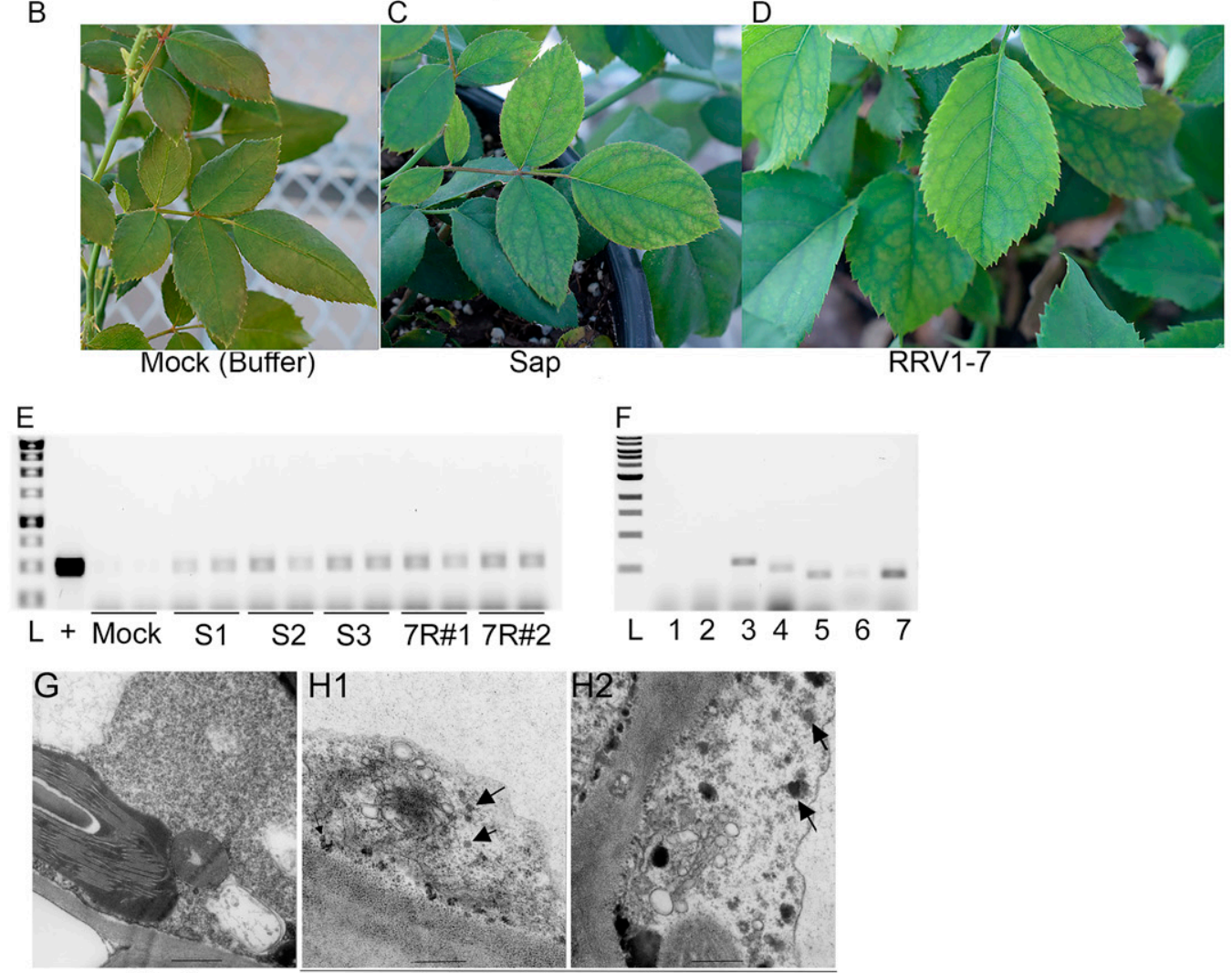

Mock

Infected Garden Rose

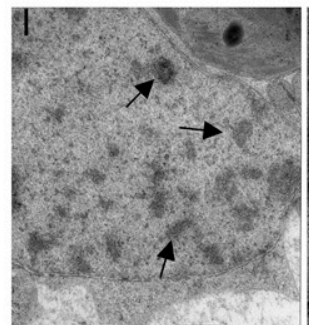

Sap Inoculated

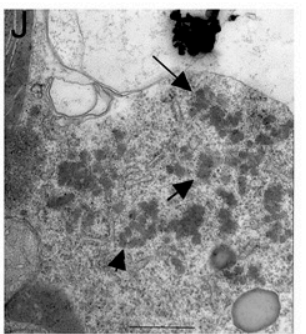

RRV1-7

Fig. 7. Successful mechanical inoculation of rose rosette virus (RRV) to roses achieved by airbrush delivery. Plants were assessed for visible symptoms; reverse transcription (RT)-PCR diagnostics and electron microscopy were used to identify virus-like particles (VLPs) and other ultrastructural changes that may be associated with RRV infection. A, The airbrush delivery method and predicted systemic movement of virus to other leaves. All rose plants used in this study had a single major stem from the soil, three "canes" extending from the major stem, and further branches that are called secondary $\left(2^{\circ}\right)$ stems. Compound leaves grew from the major canes and $2^{\circ}$ stems. Prior to inoculation, a shield was introduced to isolate a major cane that had one or two $2^{\circ}$ stems with compound leaves. The leaves were sprayed and marked. Virus spreads systemically to noninoculated leaves, illustrated as gray leaves. B to $\mathbf{D}$, Mock-inoculated and virusinfected plants at 25 days postinoculation (dpi). Plants were treated with either buffer only (Mock), sap extracted from a field-infected rose plant (Sap), or the RRV1-7 infectious clone (RRV1-7). New growth shows mild yellow mosaic and veins remain dark green, although these "symptoms" can be quite variable and, therefore, are not a reliable indicator of infection by themselves. The identity of each treatment is listed above the panels. E, Suspected systemic leaves were harvested from the plants represented in B, C, and D, and diagnostic RT-PCR tests were performed to confirm infection at 25 dpi. Image shows a $1 \%$ agarose gel containing RT-PCR products, detecting RNA4 in two leaves harvested from two different canes. The bars below the gel identify the two samples from a single plant. The PCR products represent three sap-inoculated plants (S1, S2, and S3) and infectious clone-inoculated plants $(7 \mathrm{R} \# 1$ to $7 \mathrm{R} \# 2)$. L = 1-kb ladder. The plus symbol (+) identifies a PCR product amplified from the agRNA4 cDNA. F, A cDNA sample from a systemic leaf of an RRV1-7-infected rose sample in panel E was selected for the additional RT-PCR testing shown here. The 1\% agarose gel contains representative RT-PCR tests detecting RNA1 through RNA7. RT-PCR failed to detect RNA1 and RNA2 (lanes 1 and 2), which may indicate low abundance of RNAs in systemic tissues, but detected RNA3, RNA4, RNA5, RNA6, and RNA7 (lanes 3 to 7, respectively) in inoculated rose plants. G to J, Transmission electron micrographs of ultrathin sections taken from a healthy plant (G), a garden-infected rose plant (H1 and H2), a sap-infected rose plant (I), and RRV1-7 infected rose plant (J). The scale bars in each panel represent $0.5 \mu \mathrm{m}$. The ultrathin section of a healthy rose leaf in $\mathrm{G}$ shows intact cellular contents and serves as a negative control. Images $\mathrm{H} 1$ and $\mathrm{H} 2$ are cells of a gardeninfected rose and show what appears to be membraneous bodies that aggregate in the cytoplasm that are not seen in healthy tissues. Arrows point to examples of VLPs. Ultrathin sections of infected leaves were taken from sap-inoculated (I) or RRV1-7 inoculated (J) plants. 
Three-week-old plants were infiltrated with A. tumefaciens cultures harboring constructs for each RRV agRNA segment. Cultures were grown overnight in yeast extract peptone media, were resuspended in MES buffer $\left(10 \mathrm{mM} \mathrm{MgCl}_{2}, 10 \mathrm{mM} \mathrm{MES}\right.$, $\mathrm{pH}$ 5.6, and $150 \mu \mathrm{M}$ acetosyringone), and were adjusted to an $\mathrm{OD}_{600}$ of 1.0, except agRNA3, for which we used varying $\mathrm{OD}_{600}$ concentrations. Equal volumes of Agrobacterium culture were incubated in the dark for 2 to $4 \mathrm{~h}$, then were mixed at 1.0 OD and were loaded to a 1-ml syringe for infiltration to $N$. benthamiana. Mixed Agrobacterium cultures were delivered to rose plants using the Central Pneumatic airbrush.

\section{RT-RPA.}

RPAs were performed as described by Okano et al. (2014), using total RNA $(5 \mu \mathrm{g})$ from $N$. benthamiana leaves as well as infected or healthy garden rose samples. Total RNA samples were treated with DNase I for $1 \mathrm{~h}$ at $37^{\circ} \mathrm{C}$ and were then treated with 0,1 , and $5 \mathrm{U}$ of RNase I to digest singlestrand RNA, leaving dsRNA intact. Then the dsRNA was denatured and both negative and positive strands can be amplified by RT-PCR. RNase I-treated RNA was reverse transcribed using random primers and Superscript III and were then PCR-amplified using the following primer pairs: agRRV1-F1/R1, agRRV2-F1/R1, agRRV3-F2/R2, and agRRV4-F1/R1. All PCR-amplified products were subjected to $1.2 \%$ agarose gel electrophoresis stained with ethidium bromide (Okano et al. 2014).

\section{Epifluorescence, confocal, and transmission electron microscopy.}

Leaf segments were cut with a scalpel and placed between a microscope slide and coverslip and were then examined with a Nikon Eclipse 90i epifluorescence microscope, using the fluorescein isothiocyanate filter (excitation 465 to $495 \mathrm{~nm}$; emission 515 to $555 \mathrm{~nm}$ ) to detect iLOV. Images were captured using a DS-Ri1 camera and NIS-Elements AR-3.2 software (Nikon). An Olympus FV1000 confocal microscope was used for high-resolution imaging of leaf segments. iLOV fluorescence was captured using an excitation of $488 \mathrm{~nm}$ (voltage set to 536) and emissions detector of 505 to 540 (voltage set to 770). Chlorophyll fluorescence was captured simultaneously, using emissions filter of 640 to $650 \mathrm{~nm}$ (voltage set to 770).

Rose leaf samples were resin-embedded, and ultrathin sections were prepared by the Texas A\&M University Microscopy and Imaging Core Facility. Where indicated, the Pelco Biowave microwave processor (Ted Pella, Inc.) equipped with ColdSpot technology was used, with the temperature set to $20^{\circ} \mathrm{C}$. Microwave power settings are expressed as continuous power in watts. All fixation and washing steps as well as epoxy resin infiltration with microwave processing were performed under vacuum, while the dehydration steps were performed without vacuum. Leaves were cut into 1-mm square sections immersed in Trump's fixative in a polypropylene microcentrifuge tube and were then vacuum infiltrated (McDowell and Trump 1976). Samples were kept at room temperature for $30 \mathrm{~min}$, were then microwaved at $150 \mathrm{~W}$ with a 1-3-1-2 cycle (magnetron 1 min on, 3 min off, 1 min on, 2 min off) under vacuum, and were then microwaved at $650 \mathrm{~W}$ with a $10 \mathrm{~s}$ on, $20 \mathrm{~s}$ off, $10 \mathrm{~s}$ on cycle (Ferris et al. 2009). Samples were washed three times in Trump's fixative and twice in water for $1 \mathrm{~min}$ at $150 \mathrm{~W}$ each time, were then postfixed in $1 \%$ aqueous osmium tetroxide at $100 \mathrm{~W}$ power, using five $2 \mathrm{~min}$ on, 2 min off cycles. Osmium tetroxide was replaced by $2.5 \% \mathrm{wt} / \mathrm{vol}$ aqueous potassium ferrocyanide (Sigma-Aldrich), and five $2 \mathrm{~min}$ on, $2 \mathrm{~min}$ off cycles were performed as above. This sequential osmium postfixation and reduction treatment yielded better contrast without overstaining (Hua et al. 2015), compared with the simultaneous treatment with reduced osmium. Samples were then washed in water twice for $1 \mathrm{~min}$ at $250 \mathrm{~W}$, en-bloc stained with $2 \% \mathrm{wt} / \mathrm{vol}$ aqueous uranyl acetate at $100 \mathrm{~W}$, using three 2 min on, 2 min off cycles, and were rinsed twice in water as above. Dehydration in acetone series $(10,20,40,60,80 \%$ $\mathrm{vol} / \mathrm{vol}$ acetone in water) and two times in $100 \%$ acetone was performed for $3 \mathrm{~min}$ at $200 \mathrm{~W}$, followed by $10 \mathrm{~min}$ on a rotator in each step. Infiltration with modified Quetol/Spurr's low viscosity resin (Ellis 2006) was performed under vacuum as follows: acetone/resin 1:1 mixture, $3 \mathrm{~min}$ at $200 \mathrm{~W}$ without vacuum; acetone/resin 1:1 mixture, acetone/resin 1:2 mixture, $3 \mathrm{~min}$ at $200 \mathrm{~W}$. Four changes of $100 \%$ resin followed infiltration. Each time, samples were kept on a rotator for 1 to $2 \mathrm{~h}$, then were microwaved under vacuum for $5 \mathrm{~min}$ at $200 \mathrm{~W}$. Samples were then transferred to embedding molds and polymerized at $60^{\circ} \mathrm{C}$ for two days.

Ultrathin sections were collected on 200-mesh copper grids and were stained with $2 \%$ uranyl acetate for 5 min and freshly prepared Reynold's lead citrate for 5 min. Images were acquired on a JEOL 1200Ex transmission electron microscope at the calibrated magnification using an SIA 15C CCD camera.

\section{Fluorometry.}

Fluorometry was used to assess the expression level of the iLOV protein in the three biological replicates. At different time intervals, $20 \mathrm{mg}$ of infiltrated tissue was harvested and mixed with ice-cold 0.1 M Tris- $\mathrm{HCl}(\mathrm{pH} 8.0)$ or $0.05 \mathrm{M}$ phosphate buffered saline (PBS) to make a 1:5 (wt/vol) dilution. Zirconia beads ( $2.0 \mathrm{~mm}$ size) were added to the tubes and were homogenized in a SPEX SamplePrep 1600 mini-G tissue lyser at $1,500 \mathrm{rpm}$ for $1 \mathrm{~min}$. The crude homogenate was centrifuged at $12,000 \times g$ for $5 \mathrm{~min}$, then, supernatants were aliquoted into fresh tubes. Coomassie Plus protein assay reagent (Thermo-Fisher) and QuickStart bovine serum albumin standard (Bio-Rad) were used to measure the protein concentrations of each supernatant.

The supernatants were diluted fivefold with PBS, and then, $150 \mu \mathrm{l}$ of each sample was loaded into a Nunc black polystyrene 96-well nonlidded plate. Fluorescence was initially measured using a SpectraMax iD5 microplate reader, which detects picomoles of emissions. The plate was read using 450 and $495 \mathrm{~nm}$ excitation and emission wavelength with a 400-ms integration time and automatic photomultiplier gain. For more sensitive measurements, we used spectrophotometric capabilities of the QuantStudio 5 real-time PCR machine (Applied Biosystems), which can detect femtamoles of fluorescence. A volume of $20 \mu \mathrm{l}$ of the diluted supernatant was loaded into a MicroAmp Optical 96-well reaction plate and was heated to $24^{\circ} \mathrm{C}$ and read for $15 \mathrm{~s}$, using SYBR green parameters (497 and $520 \mathrm{~nm}$ excitation and emission) because of its similarity to iLOV spectra. Raw fluorescence data were normalized to their respective protein concentration, using Microsoft Excel, to yield fluorescence units per microgram of protein.

\section{ACKNOWLEDGMENTS}

The authors gratefully acknowledge L. Zhenghe from Zhejiang University for providing the pCB301-HDV plasmid for our constructions, M. Scheiber at Star Roses and Plants for providing rose liners for experiments, The American Rose Society for providing a financial gift that enabled this research, the United States Department of Agriculture's National Institute of Food and Agriculture (NIFA) Specialty Crop Research Initiative project "Combating Rose Rosette Disease: Short Term and Long-Term Approaches" (2014-51181-22644/ SCRI), and the use of the Texas A\&M Microscopy and Imaging Center. S. Vitha and R. Littleton were particularly instrumental in embedding, sectioning, and imaging.

\section{AUTHOR-RECOMMENDED INTERNET RESOURCE}

NCBI protein archive: https://www.ncbi.nlm.nih.gov/protein 


\section{LITERATURE CITED}

Ahlquist, P., French, R., Janda, M., and Loesch-Fries, L. S. 1984. Multicomponent RNA plant virus infection derived from cloned viral cDNA. Proc. Natl. Acad. Sci. U.S.A. 81:7066-7070.

Altschul, S. F., Gish, W., Miller, W., Myers, E. W., and Lipman, D. J. 1990. Basic local alignment search tool. J. Mol. Biol. 215:403-410.

Amroun, A., Priet, S., de Lamballerie, X., and Quérat, G. 2017. Bunyaviridae RdRps: Structure, motifs, and RNA synthesis machinery. Crit. Rev. Microbiol. 43:753-778.

Babu, B., Washburn, B. K., Ertek, T. S., Miller, S. H., Riddle, C. B., Knox, G. W., Ochoa-Corona, F. M., Olson, J., Katırcioğlu, Y. Z., and Paret, M. L. 2017. A field based detection method for rose rosette virus using isothermal probe-based reverse transcription-recombinase polymerase amplification assay. J. Virol. Methods 247:81-90.

Babu, B., Washburn, B. K., Poduch, K., Knox, G. W., and Paret, M. L. 2016 Identification and characterization of two novel genomic RNA segments RNA5 and RNA6 in rose rosette virus infecting roses. Acta Virol. 60:156-165.

Bedoya, L. C., and Daròs, J. A. 2010. Stability of tobacco etch virus infectious clones in plasmid vectors. Virus Res. 149:234-240.

Bordat, A., Houvenaghel, M. C., and German-Retana, S. 2015. Gibson assembly: An easy way to clone potyviral full-length infectious cDNA clones expressing an ectopic VPg. Virol. J. 12:89.

Boyer, J.-C., and Haenni, A.-L. 1994. Infectious transcripts and cDNA clones of RNA viruses. Virology 198:415-426.

Cao, M., Ye, X., Willie, K., Lin, J., Zhang, X., Redinbaugh, M. G., Simon, A. E., Morris, T. J., and Qu, F. 2010. The capsid protein of Turnip crinkle virus overcomes two separate defense barriers to facilitate systemic movement of the virus in Arabidopsis. J. Virol. 84:7793-7802.

Chapman, S., Faulkner, C., Kaiserli, E., Garcia-Mata, C., Savenkov, E. I., Roberts, A. G., Oparka, K. J., and Christie, J. M. 2008. The photoreversible fluorescent protein iLOV outperforms GFP as a reporter of plant virus infection. Proc. Natl. Acad. Sci. U.S.A. 105:20038-20043.

Chiba, M., Reed, J. C., Prokhnevsky, A. I., Chapman, E. J., Mawassi, M., Koonin, E. V., Carrington, J. C., and Dolja, V. V. 2006. Diverse suppressors of RNA silencing enhance agroinfection by a viral replicon. Virology 346:7-14.

Chikh Ali, M., Said Omar, A., and Natsuaki, T. 2011. An infectious fulllength cDNA clone of potato virus $\mathrm{Y}(\mathrm{NTN}-\mathrm{NW})$, a recently reported strain of PVY that causes potato tuber necrotic ringspot disease. Arch. Virol. 156:2039-2043.

Christie, J. M., Hitomi, K., Arvai, A. S., Hartfield, K. A., Mettlen, M., Pratt, A. J., Tainer, J. A., and Getzoff, E. D. 2012. Structural tuning of the fluorescent protein iLOV for improved photostability. J. Biol. Chem. 287:22295-22304.

Davari, M. D., Kopka, B., Wingen, M., Bocola, M., Drepper, T., Jaeger, K. E., Schwaneberg, U., and Krauss, U. 2016. Photophysics of the LOVbased fluorescent protein variant iLOV-Q489K determined by simulation and experiment. J. Phys. Chem. B 120:3344-3352.

Desbiez, C., Chandeysson, C., Lecoq, H., and Moury, B. 2012. A simple, rapid and efficient way to obtain infectious clones of potyviruses. J. Virol. Methods 183:94-97.

Di, R., Hill, J. H., and Epstein, A. H. 1990. Double-stranded RNA associated with the rose rosette disase of multiflora rose. Plant Dis. 74:56-58.

Di Bello, P. L., Ho, T., and Tzanetakis, I. E. 2015. The evolution of emaraviruses is becoming more complex: Seven segments identified in the causal agent of rose rosette disease. Virus Res. 210:241-244.

Di Bello, P. L., Thekke-Veetil, T., Druciarek, T., and Tzanetakis, I. E. 2018. Transmission attributes and resistance to rose rosette virus. Plant Pathol. 67:499-504

Ding, X. S., Liu, J., Cheng, N.-H., Folimonov, A., Hou, Y.-M., Bao, Y., Katagi, C., Carter, S. A., and Nelson, R. S. 2004. The tobacco mosaic virus $126-\mathrm{kDa}$ protein associated with virus replication and movement suppresses RNA silencing. Mol. Plant-Microbe Interact. 17:583-592.

Dolja, V. V., McBride, H. J., and Carrington, J. C. 1992. Tagging of plant potyvirus replication and movement by insertion of $\beta$-glucuronidase into the viral polyprotein. Proc. Natl. Acad. Sci. U.S.A. 89: 10208-10212.

Ellis, E. A. 2006. Solutions to the problem of substitution of ERL 4221 for vinyl cyclohexene dioxide in spurr low viscosity embedding formulations. Micros. Today 14:32-33.

Feng, M., Cheng, R., Chen, M., Guo, R., Li, L., Feng, Z., Xie, L., Hong, J., Zhang, Z., Kormelink, R., Tao, X., and Resources, G. 2019. Rescue of tomato spotted wilt tospovirus entirely from complementary DNA clones. Proc. Natl. Acad. Sci. U.S.A. 117:1181-1190.

Ferris, A. M., Giberson, R. T., Sanders, M. A., and Day, J. R. 2009. Advanced laboratory techniques for sample processing and immunolabeling using microwave radiation. J. Neurosci. Methods 182:157-164.
Flatken, S., Ungewickell, V., Menzel, W., and Maiss, E. 2008. Construction of an infectious full-length cDNA clone of potato virus M. Arch. Virol. 153:1385-1389.

Ganesan, U., Bragg, J. N., Deng, M., Marr, S., Lee, M. Y., Qian, S., Shi, M., Kappel, J., Peters, C., Lee, Y., Goodin, M. M., Dietzgen, R. G., Li, Z., and Jackson, A. O. 2013. Construction of a Sonchus yellow net virus minireplicon: A step toward reverse genetic analysis of plant negativestrand RNA viruses. J. Virol. 87:10598-10611.

Genovés, A., Navarro, J. A., and Pallás, V. 2010. The intra- and intercellular movement of Melon necrotic spot virus (MNSV) depends on an active secretory pathway. Mol. Plant-Microbe Interact. 23:263-272.

Gerlach, P., Malet, H., Cusack, S., and Reguera, J. 2015. Structural insights into bunyavirus replication and its regulation by the vRNA promoter Cell 161:1267-1279.

Gupta, A. K., Hein, G. L., and Tatineni, S. 2019. P7 and P8 proteins of High Plains wheat mosaic virus, a negative-strand RNA virus, employ distinct mechanisms of RNA silencing suppression. Virology 535:20-31.

Hoenen, T., Groseth, A., de Kok-Mercado, F., Kuhn, J. H., Wahl-Jensen, V. 2013. Minigenomes, transcription and replication competent viruslike particles and beyond: Reverse genetics systems for filoviruses and other negative stranded hemorrhagic fever viruses. Antiviral Res. 91 : 195-208.

Hopkins, K. C., McLane, L. M., Maqbool, T., Panda, D., Gordesky-Gold, B., and Cherry, S. 2013. A genome-wide RNAi screen reveals that mRNA decapping restricts bunyaviral replication by limiting the pools of Dcp2-accessible targets for cap-snatching. Genes Dev. 27:1511-1525.

Hua, Y., Laserstein, P., and Helmstaedter, M. 2015. Large-volume en-bloc staining for electron microscopy-based connectomics. Nat. Commun. 6 : 7923

Ishikawa, K., Miura, C., Maejima, K., Komatsu, K., Hashimoto, M., Tomomitsu, T., Fukuoka, M., Yusa, A., Yamaji, Y., and Namba, S. 2015 Nucleocapsid protein from Fig mosaic virus forms cytoplasmic agglomerates that are hauled by endoplasmic reticulum streaming. J. Virol. 89:480-491.

Jackson, A. O., Dietzgen, R. G., Goodin, M. M., and Li, Z. 2018 Development of model systems for plant rhabdovirus research. Adv. Virus Res. 102:23-57.

Klemm, C., Reguera, J., Cusack, S., Zielecki, F., Kochs, G., and Weber, F 2013. Systems to establish bunyavirus genome replication in the absence of transcription. J. Virol. 87:8205-8212.

Laney, A. G., Keller, K. E., Martin, R. R., and Tzanetakis, I. E. 2011. A discovery 70 years in the making: Characterization of the rose rosette virus. J. Gen. Virol. 92:1727-1732.

Li, Y., Li, L., Fan, X., Zou, Y., Zhang, Y., Wang, Q., Sun, C., Pan, S., Wu, X., and Wang, Z. 2018. Development of real-time reverse transcription recombinase polymerase amplification (RPA) for rapid detection of peste des petits ruminants virus in clinical samples and its comparison with real-time PCR test. Sci. Rep. 8:17760.

Lindbo, J. A. 2007. TRBO: A high-efficiency tobacco mosaic virus RNAbased overexpression vector. Plant Physiol. 145:1232-1240.

Ma, X., Zhou, Y., and Moffett, P. 2019. Alterations in cellular RNA decapping dynamics affect tomato spotted wilt virus cap snatching and infection in Arabidopsis. New Phytol. 224:789-803.

Mann, K. S., Johnson, K. N., and Dietzgen, R. G. 2015. Cytorhabdovirus phosphoprotein shows RNA silencing suppressor activity in plants, but not in insect cells. Virology 476:413-418.

McDowell, E. M., and Trump, B. F. 1976. Histologic fixatives suitable for diagnostic light and electron microscopy. Arch. Pathol. Lab. Med. 100: 405-414.

Mielke-Ehret, N., and Mühlbach, H.-P. 2012. Emaravirus: A novel genus of multipartite, negative strand RNA plant viruses. Viruses 4:1515-1536.

Mitchell, A. L., Attwood, T. K., Babbitt, P. C., Blum, M., Bork, P., Bridge, A., Brown, S. D., Chang, H.-Y., El-Gebali, S., Fraser, M. I., Gough, J., Haft, D. R., Huang, H., Letunic, I., Lopez, R., Luciani, A., Madeira, F., Marchler-Bauer, A., Mi, H., Natale, D. A., Necci, M., Nuka, G., Orengo, C., Pandurangan, A. P., Paysan-Lafosse, T., Pesseat, S., Potter, S. C., Qureshi, M. A., Rawlings, N. D., Redaschi, N., Richardson, L. J., Rivoire, C., Salazar, G. A., Sangrador-Vegas, A., Sigrist, C. J. A., Sillitoe, I., Sutton, G. G., Thanki, N., Thomas, P. D., Tosatto, S. C. E., Yong, S.-Y., and Finn, R. D. 2019. InterPro in 2019: Improving coverage, classification and access to protein sequence annotations. Nucleic Acids Res. 47 (D1):D351-D360.

Mukherjee, A., Walker, J., Weyant, K. B., and Schroeder, C. M. 2013. Characterization of flavin-based fluorescent proteins: An emerging class of fluorescent reporters. PLoS One 8:e64753.

Neumann, G., Whitt, M. A., and Kawaoka, Y. 2002. A decade after the generation of a negative-sense RNA virus from cloned cDNA - what have we learned? J. Gen. Virol. 83:2635-2662. 
Okano, Y., Senshu, H., Hashimoto, M., Neriya, Y., Netsu, O., Minato, N., Yoshida, T., Maejima, K., Oshima, K., Komatsu, K., Yamaji, Y., and Namba, S. 2014. In planta recognition of a double-stranded RNA synthesis protein complex by a potexviral RNA silencing suppressor. Plant Cell 26:2168-2183.

Pemberton, H. B., Ong, K., Windham, M., Olson, J., and Byrne, D. H. 2018. What is rose rosette disease? HortScience 53:592-595.

Potter, S. C., Luciani, A., Eddy, S. R., Park, Y., Lopez, R., and Finn, R. D. 2018. HMMER web server: 2018 update. Nucleic Acids Res. 46 (W1): W200-W204.

Qian, S., Chen, X., Sun, K., Zhang, Y., and Li, Z. 2017. Capped antigenomic RNA transcript facilitates rescue of a plant rhabdovirus. Virol. J. 14:113.

Sasvari, Z., Alatriste Gonzalez, P., and Nagy, P. D. 2014. Tombusvirus-yeast interactions identify conserved cell-intrinsic viral restriction factors. Front. Plant Sci. 5:383.

Sempere, R. N., Gómez, P., Truniger, V., and Aranda, M. A. 2011. Development of expression vectors based on pepino mosaic virus. Plant Methods 7:6.

Shires, M., Ueckert, J., Ong, K., and Byrne, D. H. 2019. Rose rosette virus: Exploration of potential root transmission. HortScience 54: S337.

Shivprasad, S., Pogue, G. P., Lewandowski, D. J., Hidalgo, J., Donson, J., Grill, L. K., and Dawson, W. O. 1999. Heterologous sequences greatly affect foreign gene expression in tobacco mosaic virus-based vectors. Virology 255:312-323.

Silvestro, S. R., and Chapman, G. B. 2004. A transmission electron microscope study of "New Dawn" climber rose (Rosa wichuraiana $x$ safrano) exhibiting rose rosette disease. Plant Cell Rep. 23:345-351.

Stobart, C. C., and Moore, M. L. 2014. RNA virus reverse genetics and vaccine design. Viruses 6:2531-2550.
Sun, Y., Li, J., Gao, G. F., Tien, P., and Liu, W. 2018. Bunyavirales ribonucleoproteins: The viral replication and transcription machinery. Crit. Rev. Microbiol. 44:522-540.

Verchot, J. 2012. Cellular chaperones and folding enzymes are vital contributors to membrane bound replication and movement complexes during plant RNA virus infection. Front. Plant Sci. 3:275.

Verchot, J. 2016. How does the stressed out ER find relief during virus infection? Curr. Opin. Virol. 17:74-79.

Walia, J. J., and Falk, B. W. 2012. Fig mosaic virus mRNAs show generation by cap-snatching. Virology 426:162-166.

Waliczek, T. M., Byrne, D., and Holeman, D. 2018. Opinions of landscape roses available for purchase and preferences for the future market HortTechnology 28:807-814.

Wang, L.-Y., Lin, S.-S., Hung, T.-H., Li, T.-K., Lin, N.-C., and Shen, T.-L. 2012. Multiple domains of the tobacco mosaic virus p126 protein can independently suppress local and systemic RNA silencing. Mol. PlantMicrobe Interact. 25:648-657.

Wang, Q., Ma, X., Qian, S., Zhou, X., Sun, K., Chen, X., Zhou, X., Jackson, A. O., and Li, Z. 2015. Rescue of a plant negative-strand RNA virus from cloned cDNA: Insights into enveloped plant virus movement and morphogenesis. PLOS Pathog. 11:e1005223.

Weber, P. H., and Bujarski, J. J. 2015. Multiple functions of capsid proteins in (+) stranded RNA viruses during plant-virus interactions. Virus Res. 196:140-149.

Williams, B., Verchot, J., and Dickman, M. B. M. B. 2014. When supply does not meet demand-ER stress and plant programmed cell death. Front. Plant Sci. 5:211.

Yu, C., Karlin, D. G., Lu, Y., Wright, K., Chen, J., and MacFarlane, S. 2013. Experimental and bioinformatic evidence that raspberry leaf blotch emaravirus P4 is a movement protein of the $30 \mathrm{~K}$ superfamily. J. Gen. Virol. 94:2117-2128. 